\title{
Synthesis and docking of new benzimidazole derivates designed as novel and potent $\mathrm{CB}_{1}$ cannabinoid ligands.
}

\author{
Romero-Parra J.*, Lagos C.F.;Espinosa-Bustos C., Mella-Raipán J; Pessoa-Mahana., Recabarren G., \\ Pessoa-Mahana C. D. \\ ${ }^{1}$ Departamento de Farmacia, Facultad de Química, Pontificia Universidad Católica de Chile Vicuña \\ Mackenna 4860, Casilla 306, Santiago 22, Chile \\ ihromero@uc.cl
}

Keywords: Cannabinoids. Benzimidazole. Heterocycles.

\section{INTRODUCTION}

Despite the fact that medicinal and cognitive effects of Marijuana (Cannabis sativa) have been known for thousands of years, only recent studies provided convincing information on the biological mediation of it effects. Currently, two subtypes of cannabinoid receptor (namely $\mathrm{CB}_{1}$ and $\mathrm{CB}_{2}$ ) have been cloned and pharmacologically characterized. Both $\mathrm{CB}_{1}$ and $\mathrm{CB}_{2}$ belong to the $\mathrm{G}$ protein-coupled receptor family (GPCRs) ${ }^{1}$.

Knowledge of the characteristics of $\mathrm{CB}_{1}$ binding site has notably increased the interest on the synthesis of new small molecules as potential ligands, significantly less lipophilic and more potent than $\Delta 9$ $\mathrm{THC}^{2}$. Our interest in developing new cannabinoid ligands is based on the therapeutic opportunities associated to these chemical entities.

\section{RESULTS AND DISCUSSION}

The aim of this study is to obtain new cannabinoids ligands, trying to emulate the powerful indole cannabinoid agonist WIN 55,212-2 (see Figure 1) by replacing the indole by the isostere ring benzimidazole.

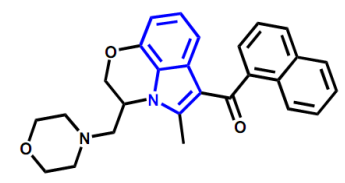

Figure 1: Cannabinoid agonist WIN 55,212-2. Blue bonds represent the heterocycle frame to be replaced.

Benzoimidazole series have been synthesized by oxidative condensation of 1,2-phenylenediamine with commercially available aldehydes. Substitution reactions in the $\mathrm{N} 1$ of the benzimidazole were carried out by using acid halides. Figure 2 shows the reaction conditions for the obtaining of heterocycle framework and the substitution of the $\mathrm{N} 1$ of the benzimidazole.

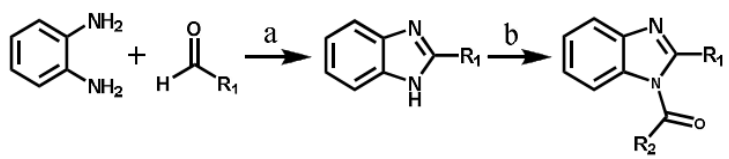

Figure 2: Synthetic secuence to the obtaining of target benzimidazoles. a) Ethanol, reflux. b) acid halides, triethylamine, THF, $6 h$

To date twelve benzimidazole derivates have been synthesized, which possess a short chain aliphatic portion in position 2 and an aromatic substitution on the N1. This last substitution will give us valuable information about the contribution of the naphthalene moiety in WIN 55,212-2 to the total energy binding. Therefore, we included this moiety in six compounds meanwhile the other six molecules bear a 4-methoxyphenyl in this position. The series was subjected to experiments and then compared the results with WIN 55,212-2 binding $\Delta G$, which value is $-8.50 \mathrm{kcal} / \mathrm{mol}$. In silico study suggest that all molecules have a similar ability compaired with WIN 55,212-2 to interact into the binding site of the receptor $\mathrm{CB}_{1}$. Table 1 shows synthesized benzimidazole analogues and their calculated binding $\Delta \mathrm{G}$.

\begin{tabular}{|c|c|c|c|}
\hline $\mathbf{R}_{\mathbf{1}}$ & $\mathbf{R}_{\mathbf{2}}$ & Yield (\%) & $\begin{array}{c}\text { 8inding } \mathbf{\Delta} \mathbf{G} \\
\text { (kcal/mol) }\end{array}$ \\
\hline 1-Naphtyl & Methyl & 78 & -6.55 \\
\hline 1-Naphtyl & Propyl & 66 & -5.54 \\
\hline 1-Naphtyl & Butyl & 51 & -5.66 \\
\hline 1-Naphtyl & Isospropyl & 84 & -6.31 \\
\hline 1-Naphtyl & 2- Methyl propyl & 56 & -6.71 \\
\hline 1-Naphtyl & Cyclopenthyl & 81 & -6.33 \\
\hline 4-Methoxyphenyl & Methyl & 33 & -5.81 \\
\hline 4-Methoxyphenyl & Propyl & 24 & -5.65 \\
\hline 4-Methoxyphenyl & Butyl & 21 & -5.67 \\
\hline 4-Methoxyphenyl & Isospropyl & 42 & -5.07 \\
\hline 4-Methoxyphenyl & 2- Methyl propyl & 50 & -6.40 \\
\hline 4-Methoxyphenyl & Cyclopenthyl & 28 & -8.96 \\
\hline
\end{tabular}

Table 1: $\Delta$ G Binding values.

\section{CONCLUSION}

The synthesis of a series of benzimidazole derivates structurally referible to WIN 55,212-2 have been afforded. The in silico docking studies predicts a good binding affinity like the agonist indole.

\section{ACKNOWLEDGEMENTS}

The authors are grateful to FONDECYT (grant no. 1100493) and CONICYT for doctoral support.

\section{REFERENCES}

[1] B. Bosier, Giulio G. Muccioli, E.Hermans, D. M. Lambert. Biochemical Pharmacology 2010, 80, 1-12.

[2] Pál Pacher, Sándor Bátkai, and George Kunos. Rev Article. Pharmacol Rev. 2006, 58, 389-462. 